\title{
THE GRAMMATICALIZATION OF SPECIFICITY (AND BEYOND) IN BORUCA ${ }^{1}$
}

\section{J. Diego Quesada}

\section{Introduction}

SPECIFICITY, as many other concepts of human experience, has various linguistic manifestations across languages, varying from lexical expression, e.g. adjectives, as in the English example in (1), to distinctions which make use of categories existing in the grammatical repertoire of a given language, as in Spanish (2), where the distinction between subjunctive and indicative serves to express a distinction of specificity; ${ }^{2}$ in other cases, a given morpheme takes on the function of expressing that notion; that is the case of Boruca (3), a Chibchan language of Costa Rica, where the clitic $k i$, an erstwhile demonstrative pronoun, has undergone further grammaticalization to eventually become a SPECIFICITY marker:

(1a) I'm looking for a lawyer

(1b) I'm looking for a specific/certain/given lawyer

(2a) Busco una muchacha que sepa coser

'I'm looking for a girl who knows-SUBJC how to sew' [who I do not know]

(2b) Busco (a) una muchacha que sabe coser

'I'm looking for a girl who knows-INDIC how to sew' [who I know]

(3a) At kiya'do'-rae'tse ramróhk tíshibi' e'de

1SG SUBJREFLmarry-PRESone woman Térraba with

'I will marry a woman from Térraba' [who I don't know]

(3b) At kiya'do'-rae'tse ramróhk tíshibi' $\underline{k i} \quad e^{\prime} d e$

1SG SUBJREFLmarry-PRESone woman Térraba SPEC with

'I will marry a woman from Térraba' [who I know]

In Boruca the difference between (3a) and (3b) is one of specificity, just as that between (1a) and (1b), and (2a) and (2b). The development of the marker ki up to this point constitutes the main interest of this paper. Whereas there is little doubt about the nature of the conceptual structure of SPECIFICITY (see 2., below), the channel followed by a given language in the grammaticalization of this notion, to my knowledge, has not been the subject of any case study concerned with grammaticalization processes. The task of this paper will therefore consist in showing this development.

This paper is organized as follows: Section 2 discusses the problem of reference and the place of SPECIFICITY within this complex cognitive domain. Section 3 deals in detail with the grammaticalization of SPECIFICITY; it presents the current functions of the clitic $k i$ with some space

\footnotetext{
${ }^{1}$ In International Journal of American Linguistics (IJAL) 2000, 66 (3): 549-562.

${ }^{2}$ In other cases the presence of the topicality marker $a$ also helps to achieve a specific reading in this language (see Quesada 1995 for details).
} 
devoted to its distribution in regard to both syntactic relations and word class of the noun phrases it marks as specific. Finally, Section 4 summarizes the results of the study.

\section{Reference and SPECIFICITY}

In his influential article "On Referring” Strawson (1950/1993) defines 'referring' as "a characteristic of a use of an expression, just as 'being about' something, and truth-or-falsity, are characteristics of a use of a sentence" [emphasis in original], and establishes a difference between referring on the one hand and meaning ("function of the use of an expression") on the other. By asserting that "We do not, and we cannot, while referring, attain the point of complete explicitness at which the referring function is no longer performed. [but rather] The actual unique reference made, if any, is a matter of the particular use in the particular context; the significance of the expression used is the set of rules or conventions which permit such references to be made", Strawson (1993: 70) points at an essential characteristic of reference, namely its being contextdependent; in this sense reference comes to border on deixis; hence his contextual requirement for referring, "that the thing should be in a certain relation to the speaker and to the context of utterance" (1993: 72). Lyons maintains the principle of context-dependency of reference, "The term 'reference'... has to do with the relationship which holds between an expression and what that expression stands for on particular occasions of its utterance" (Lyons 1977: 174); and distinguishes between singular and general referring expressions, where the former refer to individuals, while the latter refer to classes thereof. In addition to these two types, Lyons distinguishes between definite expressions, those referring to a specific individual, and indefinite expressions, those which do not refer to a specific individual or class. Of these four types of reference, singular definite is regarded as basic (it comprises three kinds of expressions, definite noun phrases, proper names, and personal pronouns.) Within the realm of definite reference, Lyons includes non-referring definite noun phrases, expressions that despite being definite do not identify particular, specific entities. More directly related to our concern in this paper, is the opposition between specific and non-specific indefinite reference. Lyons' point of departure is the distinction between non-definite (any noun phrase which is not definite) and indefinite (an indefinite pronoun or a noun phrase introduced by an indefinite article) noun phrases. Indefinite phrases can be used specifically or non-specifically; Lyons (1977: 188) remarks in this respect that "very often... we cannot tell whether an indefinite noun-phrase is being used with specific reference or not"; he points as well to the fact that languages that have definite and/or indefinite articles vary in the way that they make use of them. Indefinite pronouns and noun phrases introduced by indefinite adjectives (e.g. English some) are subject to a specific/non-specific interpretation. It follows, then, that specificity is "a reading" the speaker assigns to certain NPs, whereby the entity referred to is particularized, that is, "isolated" from the set of akin elements. Languages can grammaticalize this option in such a way that whenever a speaker is construing an entity (definite or indefinite) as specific s/he has to mark it as such using the means available. As will be shown in 3, the grammaticalization of SPECIFICITY in Boruca confirms Lyons' classification not only in that indefinite NPs can be marked for specificity, but also in that it was the erstwhile definite article that was "recruited" to express that distinction of reference even with noun phrases introduced by the indefinite article.

Givón adds a new concept -already latent in Lyons- to the discussion of reference, which can be taken as the necessary step to operationalize Strawson's contextual requirement, namely referential intent; in his words, "The facet of referentiality in language is related to the fact that 
reference involves the universe of discourse (rather than the real world.) Unlike in logic, in human language speakers and hearers negotiate the scope of the particular universe they talk about, and also establish the identities of individuals ('arguments') they intend to take for granted as existing within that universe [emphasis in original]" (Givón 1984: 390). This implies a distinction between semantic and pragmatic reference, where the former relates to the scope of propositions as isolated utterances while the latter involves the universe of discourse, actual performance and intent. As we will see in 3, in terms of grammaticalization of dimensions of reference, it is pragmatic reference that originates chains; usually the cause is the need for referential emphasis.

It has become clear thus far that reference involves the act of establishing a link between a linguistic unit designed to identify referents and some entity in the universe of discourse. It is, moreover, legitimate to assume that the act of referring is central to human language and that, as such, individual languages tend to grammaticalize facets of reference such as DEFINITENESS, INDIVIDUATION (singularity), SPECIFICITY, and so on. Context-dependency, then, has to do with the actual use of the elements available in a language, whereas the grammatical (and grammaticalized) notions (and forms) reflect both the ontological need to refer and the dimensions of reference that are relevant in one language (and culture).

\subsection{Definiteness vs. indefiniteness}

Reference comprises the linguistic location (semantic reference) and the intention behind locating (pragmatic reference) a given entity in discourse. The relation between these two facets of reference yields the various dimensions of reference, the two most important being definite and indefinite, which, according to Givón (1984: 3991) differ from each other in the degree to which the speaker assumes the hearer to be able to assign unique reference to an entity. ${ }^{3}$ This assumption is conditioned, among other things, by shared knowledge, immediate deictic availability (which can be absolute or indirect; the former implies the two main participating entities, the 'I' and the 'you'; the latter involves parts of wholes, once these are introduced in the discourse), and immediate discourse; these conditioning factors are termed by Givón the permanent file, as opposed to the active file, which pertains the specifics of every individual discourse. The two "files" are related in such a way that "within the reference-related portion of the active file, terms from the permanent file referring to unique individuals have the same status -in terms of assumptions speakers make about what hearers know- as terms referring to unique individuals entered into the file through the specific discourse" (Givón 1984: 401). Thus, if we acknowledge (and there is no reason why we should not) that reference is a context-dependent activity, it becomes easy to understand that certain referring expressions do not have a mechanical use and function; for instance, definite articles need not always be referring in a unique and specific way, that is, one instance of the may not correspond to another instance thereof depending on context, where one can be definite, even specific, and the

\footnotetext{
${ }^{3}$ Strawson (1993: 76) had come close to this by remarking that "The difference between the use of the definite and indefinite articles is, very roughly, as follows. We use 'the' either when a previous reference has been made, and when 'the' signalizes that the same reference is being made; or when, in the absence of a previous indefinite reference, the context (including the hearer's assumed knowledge) is expected to enable the hearer to tell what reference is being made. We use ' $a$ ' either when these conditions are not fulfilled of [sic] when, although a definite reference could be made, we wish to keep dark the identity of the individual to whom, or which we are referring".
} 
other generic; ${ }^{4}$ just as one instance of a may not correspond to another (cf. Mufwene 1980, 1981. The same is true of other referential markers in other languages (details in Givón 1984: 412f); this does not deny the possibility of assigning a core meaning to a form, though. Actually, this "fuzzy" property of reference markers is a manifestation of (the gradation) of a scale of referentiality, which comprises the following points (Givón 1984: 407):

DEFINITE $>$ REFERENTIAL-INDEFINITE $>$ NON-REFERENTIAL $>$ GENERIC

Givón's idea of referentiality is clearly related to referring to specific referents; but the preceding scale does not include the dimension of SPECIFIC. The scale can thus make that distinction explicit by placing it as its leftmost point:

SPECIFIC $>$ DEFINITE $>$ REFERENTIAL-INDEFINITE $>$ NON-REFERENTIAL $>$ GENERIC

This enlarged scale represents a continuum of individuation going from most precise (to the left) to least precise (to the right). As usual, individual languages grammaticalize different cut-off points. The next section deals with how Boruca's segmentation of the continuum took place.

\section{The grammaticalization of SPECIFICITY}

This section deals with the further grammaticalization of the clitic ki in Boruca. ${ }^{5}$ This clitic underwent the common path, first discussed in detail by Greenberg (1978), starting out as a definite article (Greenberg's Stage I), as illustrated in (4), and then becoming a marker of specificity (Greenberg's Stage II), as in (3a-b) above, repeated here as (5a-b):

(4) $u k i$

houseDEF

'The house'

(5a) at kiya'do'-rae'tse ramróhk tíshibi' e'de

1SG SUBJREFLmarry-PRESone woman Térraba with

'I will marry a woman from Térraba (who I don't know)'

(5b) at kiya'do'-rae'tse ramróhk tíshibi' $k i \quad e^{\prime} d e$ 1SG SUBJREFLmarry-PRESone woman Térraba SPEC with

${ }^{4}$ I concur with Givón in that generic reference, by virtue of its alluding to types is definite, but disagree when he states that for a generic NP to be rendered/perceived as definite, it must first be introduced in the discourse and then referred to. Rather, it seems, the relationship between generic and definite character obtains from the fact that generic types are all members of the permanent file, concretely the area of shared knowledge; this explains what Givón himself mentions, namely that a large number of languages code generic NPs as definite.

${ }^{5} \mathrm{Ki}$ will be glossed according to its various functions, namely as DEF (definite article); SPEC (specificity marker or specifier), not be confused with the structural position in the Government and Binding approach daughter of XP, sister to X; and SUBJ (subject). See Quesada and Quesada-Pacheco (1995) on the origin of $k i$. 
'I will marry a [certain] woman from Térraba (who I know)'

As a definite article, $k i$ underwent a series of extensions that include co-presence with proper names (6), demonstratives (7), ${ }^{6}$ and pronouns (8):

(6) Cuasrán kikawi'-raBrúnkahk tá

Cuasrán DEFlive-PRESBoruca in

'Cuasrán lives in Boruca'

(7) wá kisi'kwa ki

DEM DEFforeigner DEF

'This foreigner'

(8) At ki wá ki ramróhk beyáng-ra

1SG SUBJ DEM DEFwoman love-PRES

'I love that woman'

The uses/contexts of $k i$, as exemplified in (6-8), can be ordered in a unidirectional path going from less to more grammaticalized (nouns are lexical items while pronouns are grammatical elements): a. nouns $>$ b. proper nouns $>$ c. demonstratives $>d$. (subject) pronouns. In the stages a. and b., $k i$ functions as a definite article, whereas in stage d. it has become a marker of subjects (see below). Stage c. represents a turning point in that the expression of definiteness, as explained in 2 ., is still part of the function of $k i$ but its use with demonstratives already points at a further step in the grammaticalization process, namely rendering the referent as specific. ${ }^{7}$ This path reveals a continuum of referentiality involving different manifestations of the superordinate function of linguistic (semantic and pragmatic) location. This path, too, provides an example of what Heine (1992) calls 'grammaticalization chains', that is, linear structures characterized by their position relative to two endpoints one of which represents a higher degree of grammaticalization; the members identified in a chain (in this case the word classes to which $k i$ cliticizes) can be ranked in terms of their degree of grammaticalization such that the closer to one of the endpoints, the higher/lower the degree of grammaticalization. Furthermore, 'grammaticalization chains have the

\footnotetext{
${ }^{6}$ Greenberg (1978: 76) discusses a similar phenomenon in Rumanian, where the erstwhile demonstrative cel $(<$ Lat. ecce illum) became a definite article and now follows the sequence $[\mathrm{N}+$ definite article (suffix)] + definite article:

(i) om-ul cel cu boi man-DEF DEF with cow

'The man with cattle'

${ }^{7}$ According to Greenberg (1978: 77), "specific demonstratives, as they become bleached of deixis by anaphoric uses, are constantly being replaced by new demonstratives usually formed from the older ones by the addition of new deictic elements, by reduplication, etc. These in turn lose their deictic force to be replaced by others". In the case of $k i$, it did not lose its deictic force, but rather extended it to other parts of speech within the domain of reference.
} 
characteristics of polythetic classes which can be described as family resemblance categories' (Heine 1992: 361). Thus, it is not the case that all members in the chain have to share all defining properties; rather their contiguity is established on the basis of features shared by the adjacent members. ${ }^{8}$

\subsection{A continuum of SPECIFICITY}

Let us now concentrate on the section of the continuum of referentiality where ki moves from definiteness to specificity. In addition to cliticizing to nouns, as a definite article, $k i$ began to cliticize to other word classes, basically to full demonstrative NPs and to pronominal NPs (which can consist of personal and demonstrative pronouns), both being -according to Lyons- expressions of the basic type of reference, singular definite. Consequently, the first step in order to get a closer picture of how the new function of marker of SPECIFICITY was acquired consists of illustrating the behavior of $k i$ with these word classes, in terms of both the three grammatical relations in Boruca (subject, object, postpositional object) and semantic case roles in which ki-marked NPs appear.

Proper nouns are obligatorily ki-marked if they are subjects (cf. 6, above), and optionally if direct objects (9) and objects of postpositions $(10,11)$ :

(9) At ki Sibú (ki) beyang-ra

$1 \mathrm{SG} k i$ God $(\mathrm{ki})$ love-PRES

'I love God'

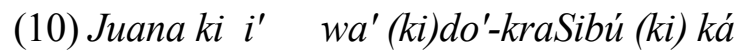

Juana $k i$ 3POSS son $(k i)$ give-PERFSibú $(k i)$ to

'Juana offered her son to God (in sacrifice)'

(11) $U$ ki rut-kráSibú (ki) úge'

House DEF burn-PREFGod $(k i)$ because

'The house burned because of God's wrath'

Demonstrative NPs show obligatory $k i$-marking as subjects (12), but optional as direct objects (13), and as objects of postpositions (14): ${ }^{9}$

\footnotetext{
${ }^{8} \mathrm{An}$ anonymous reviewer of $I J A L$ remarks that there is no historical evidence about the path taken by $k i$, as suggested here and that "the only data which we have to work with is the wide range of synchronic functions which this clitic has". This remark strikes me as naive in view of the recent insights produced by grammaticalization studies, one of them being the fact that increasing grammaticalization implies more abstract meanings and functions; similarly, synchronic variation (usually analyzed in terms of "polysemy") is widely accepted as an indicator of coexisting grammaticalization stages (cf. Lehmann 1985, 1995; Heine et al. 1991a, 1991b; Hopper and Traugott 1993).

${ }^{9}$ In Boruca, there are two classes of demonstratives; those to which ki cliticizes, wá and yá (12 illustrates the former), and those to which it does not, wé and chi' (the latter is illustrated in 14). The reason for this syntactic behavior lies in the lower degree of grammaticalization of the first class, which emerged after the rise of $k i$. In terms of ki-marking of the whole NP in which they appear, however, both classes behave in the same way, as both (12) and (14) show.
} 
(12) Wá kisi'kwa kika'yeng-ra Pedro

DEM kiforeigner $k i$ call-PRES Pedro

'This foreigner is called Pedro'

(13) Cuasrán ki wá kisi'kwa (ki)kong-kra

Cuasrán ki DEM kiforeigner $(k i)$ scare-PERF

'Cuasrán scared this foreigner'

(14) Chi' ú (ki) tákawí-r-ingróhk

DEM house $(k i)$ inlive-PRES-3PL

'They live in this house'

In the case of personal pronouns, however, only those in subject function can be ki-marked, as in (9), above; the other grammatical relations do not allow cliticization of $k i$, compare (15) and (16):

$(15) *$ At kibahd-r-ing

$1 \mathrm{SG}\left({ }^{*} \mathrm{OBJ}\right)$ hit-PRES-3SG

'He hits me'

$(16)^{*}$ At kikwik-krái $\quad k i \quad$ mang

$1 \mathrm{SG}$ (SUBJ)dance-PERF3SG (*OBL) with

'I danced with her'

The distribution of $k i$ as it correlates with grammatical relations is summarized in $\mathrm{S} 1$. In S1, + means obligatory, \pm means intermittent (sometimes 'yes', sometimes 'no', depending on the speaker's intention), while - means impossible (ungrammatical) marking. ${ }^{10}$ S1 reveals two important aspects. First, the word classes (and their referents) which are or can be ki-marked form a continuum of lexical specificity, that is, the referents of these word classes are clearly S1Kimarking by grammatical relation

\footnotetext{
${ }^{10}$ In $\mathrm{S} 1$ (as well as in the entire analysis), common nouns have not been taken into consideration for obvious reasons: the presence of $k i$ with them is straightforwardly an instance of a definite NP (though a specific reading should not be discarded a priori, cf. Section 2); it is cases like those exemplified in 3 that need an explanation, since these are the ones where the presence of a "definite article" becomes somewhat special. Definite articles with demonstratives occur in Greek, cf. afto to spiti 'this the house' and with proper nouns in other languages, cf. Italian il Giuseppe; what makes the case of ki interesting is the existence of a series of combinatorial possibilities in one single form. In addition, restrictions on the use of $k i$ with proper nouns (cf. (23) below) hint at a different state of affairs than the mere definite article + proper noun syntagm.
} 
PROPER NOUNSDEM. NPSPRONOUNS

SUBJECT +++

DIRECT OBJECT \pm \pm -

OBLIQUE \pm \pm -

specific in the case of proper nouns, but as they move to the right, specificity decreases; the deictic nature of pronouns (and, to a lesser degree, of demonstratives) makes them "lexically non-specific"; only with reference to a discourse situation do they acquire their full referential force: John Doe is more specific than $h e$. The use of $k i$ with pronouns has thus to do with the need to reinforce the referential force of these forms (see further down). Second, $k i$-marking is sensitive to grammatical relations; while subjects need to be $k i$-marked (and in the case of pronominal NPs we saw that the difference between subject and object lies precisely in the presence -subject- vs. absence -object- of $k i$ ), direct objects and obliques are optionally marked if full NPs and cannot (must not) be marked if pronominal. This begs the question of why having the same form for subject and object functions personal pronouns are $k i$-marked only for the former. Presumably, this has to do with the need to differentiate otherwise formally indistinguishable anaphoric forms, subject and object noun phrases, the core syntactic categories in Boruca; and since -as explained by Greenberg (1978: 740), subjects outrank objects, it was the former that received ki-marking; in other words, the spreading of $k i$ to pronouns only when these function as subjects has both a language-internal and a cross-linguistic basis. This is part of the process of the 'morphologization' of subject in this language, which moves towards greater differentiation between subject and object noun phrases (details in Quesada in progress). This also explains why proper nouns in subject relation are treated differently from those in the other grammatical relations. In this sense, the obligatory status of $k i$ with subject NPs, as well as the ungrammaticality of $k i$-marked non-subject pronominal NPs hints at a further stage beyond the grammaticalization of SPECIFICITY in the language, namely the reinforcement of the personal pronoun paradigm (the sequence pronoun + clitic in subject function is highly bonded in Boruca). ${ }^{11}$ In other words, obligatory ki-marking is no longer related to SPECIFICITY (though it came about therethrough), but to subjecthood (cf. Quesada in progress). As for intermittent marking, this simply shows the dependency of SPECIFICITY on discourse (as any other distinction in the domain of reference, cf. 2, above); it depends on the speaker's intention to reinforce a referent's saliency. ${ }^{12}$

11 The grammaticalization channel DEFINITENESS $>$ SPECIFICITY > SUBJECT is interesting because it reveals a connection of features that are present in one way or another in most definitions of the category of subject (e.g. Givón 1984, Comrie 1989). That is, it provides evidence of a route to subjecthood.

${ }^{12} \mathrm{Cf}$. the following case, where there is intermittent marking of the same referent in the same grammatical relation, which can be only be explained as the a difference in saliency assigned (more in ii, less in i) to the referent; this is evidenced by the fact that the snake and the woman are the central characters of the story where the examples are taken from, named Tebek kráng igi ték, 'The story of the big snake'. Yet in one case the snake is ki-marked, while in the other it is not. In other words, the snake is a referential, definite, entity in all instances in the text, and the fact that in (i) it is not $k i$-marked does not make it nonreferential. The difference is thus not one of definiteness but one of specificity:

(i)...yá kiramróh ki chéát-irátebek ék

DEM kiwoman ki ill-IMPsnake of

'That very woman was expecting a child from the snake' 
Actually, the grammaticalization of SPECIFICITY (and beyond) in Boruca has been discourse-bound from the start in that it has proceeded from contexts of definiteness (an indisputably discourse feature) to contexts characterized by the need to reinforce the referentiality of a linguistic expression -usually one lacking lexical specificity- whose reference was attained in discourse (again John Doe vs he).

Let us now turn to the behavior of $k i$ in terms of semantic case roles. There does not seem to be a one-to-one correlation between semantic case role and SPECIFICITY marking, although in the case of agents, these tend to be ki-marked regardless of the type of NP, proper nouns (17), demonstrative (18), or pronominal (19), which -as was said above- ought to be the case:

(17) Sibu ki kak kirung-krá

God ki place DEFdestroy-PERF

'God destroyed the city'

(18) Chi auh kiJuan (ki)tu'-krá

DEM dog kiJuan (ki)bite-PERF

'This dog bit Juan'

(19) I ki atbahd-ra

3SG kilsGhit-PRES

'He hits me'

As for patients, $k i$-marking is optional with proper nouns (cf. (18) above) and demonstrative patient NPs, (13) above, but ungrammatical if pronominal, as in (15) above. Similarly, benefactives allow $k i$-marking optionally if they are proper nouns (10 above), and demonstrative NPs, as in (24) below. Ki-marked pronominal benefactives are ungrammatical (21); again this is to be expected from the fact that this semantic case role usually takes the form of a postpositional phrase: ${ }^{13}$

(20) At kie'tse deterádo'-kráchi' auh (ki) ká

1SG kione bonegive-PERFDEM dog $(\mathrm{ki})$ to

'I gave a bone to that dog'

(21) E'tse drahchínadó'-kr-ingi (*ki) ká

(ii) Yá ki ramróhya ki e'sidí bra'é-irayá ki i kóngróh tebek

DEM $k i$ womanDEM $k i$ inlaugh be-IMPDEM $k i 3$ POSS man snake

kiédé,i kagrú édé

$k i$ with,3POss husband with

'Then that very woman would laugh a lot with her [own, very] snake-husband, with her devil' (Constenla and Maroto 1986: 50).

${ }^{13}$ Boruca behaves like English in terms of the treatment of subject NPs in that participants that constitute the onset of the predication are made subjects regardless of their semantic case role: I hear X, I like X, I fear $X$, I receive $X$. 
One orangegive-PERF-3SG3SG $(* k i)$ to

'He gave an orange to him'

Finally, other case roles such as locative (22) and instrumental/comitative NPs -syntactically postpositional phrases-, as in (16), show intermittent ki-marking with demonstrative NPs:

(22) we'mangkrá (ki) édéupchíh-kr-ingrohk

DEMmachete $(k i)$ withwork-PERF-3PL

'They worked with that machete'

With pronouns, the use of $k i$ is ungrammatical (cf. 16, above); the same is true of proper nouns, as illustrated in (23), below; the ungrammaticality of (23) shows that the presence of $k i$ with proper nouns (where it is possible) is not an instance of proper noun + definite article (otherwise there should be no restriction), but has to do with a distinction of some other kind:

(23) Te-kr-ingróhkMaria (*ki) e'de

speak-PERF-3PLMaria $\left({ }^{*} k i\right)$ with

'They spoke with Maria'

S2 illustrates the distribution of $k i$ as it correlates with semantic case roles:

S2Ki-marking by semantic case role

PROPER NOUNSDEM. NPSPRONOUNS

AGENT +++

PATIENT \pm \pm -

BENEFACTIVE \pm \pm-

LOCAT./INSTR.- \pm -

$\mathrm{S} 2$ shows great consistency with $\mathrm{S} 1$; the obligatory use of $k i$ with agents has to do with the fact that this semantic case role is more often than not reserved for subjects; the same is true in the case of patients, which almost always are direct objects. The impossibility of ki-marking for nonsubject pronouns is ratified too, and the fact that only pronominal agents can be $k i$-marked is closely related to their being subjects. The area of discrepancy is the impossibility of instrumental/locative proper nouns to be $k i$-marked. At present I have no readily available explanation for this. In general, however, there is intermittent marking caused by discourse saliency (cf. footnote 11). Intermittent $k i$-marking, however, does not mean than the grammaticalization of the clitic as a marker of SPECIFICITY has not been completed; it only means that in contexts where a given NP can be rendered specific, that "reading" can be attained by using $k i$, just as NPs are sometimes rendered definite and sometimes indefinite, generic, and so on.

\subsection{The final step to SPECIFICITY}

That the process at hand involves SPECIFICITY rather than any other category of linguistic location is shown not only by the increasing lack of lexical specificity and consequent increase of (selective) $k i$-marking discussed above, but also by the behavior of $k i$ in relation to indefinite NPs, 
as in (3), at the onset, and (24) below: ${ }^{14}$

(24) E'tse sukia ki daba-kra duhbi'kita

One sukia $k i$ come-PERF yesterday

'A given/certain/specific sukia came yesterday'

At first sight the use of a definite article with indefinite NPs appears contradictory; a formal description based on binary features for a sentence like (24) would look like [NP + indefinite, + definite]! The presence of $k i$ in sentences like (24) conclusively points to a new function of this clitic, SPECIFICITY. The sukia in (24) is specific at least in the speaker's (though not necessarily in the hearer's) perspective. The implication of (24) for a scalar representation of referentiality is that there is a higher degree of reference of entities above the $[ \pm$ DEFINITE] dichotomy.

The "leap" of $k i$ to mark indefinite NPs presupposes a previous series of functions, that is a grammaticalization chain, which transformed its original function into one of marker of specificity; for it is hard to conceive a one-step process which makes a definite article harmonious with indefinite NPs. It is thus legitimate to assume that the extension of $k i$ to indefinite NPs was concomitant with the generalization of $k i$ to subject pronouns, since the presence of a -now fuzzy in function- definite article with personal pronouns is one of reinforcement, cf. at ki, ba ki, $i k i=$ 'I, you, s/he and only I/you, s/he'; and this new specifying/reinforcing function can now be extended to any referent regardless of its definiteness.

One last word concerning this concrete case of grammaticalization of SPECIFICITY is in order. Going back to Lyons' classification of referring expressions, it is interesting to note that he locates the $[ \pm$ SPECIFIC] distinction within the indefinite type; the reason for that should now be obvious: it is within the domain of indefiniteness that a specific intent can most readily be detected, since in the case of definite entities the border line between DEFINITENESS and SPECIFICITY is rather fuzzy. Precisely this is what the extension of $k i$ to indefinite NPs achieves in Boruca; it not only evidences the new grammatical distinction in the grammar of reference in this language, but also links the two types of singular reference (definite and indefinite) by means of a common denominator, specific reference. This semantic duality finds its formal correlate in the apparent contradictory behavior of $k i$.

\section{Conclusion}

The process whereby a new distinction in the domain of reference became grammaticalized in Boruca constitutes an interesting case for both Chibchan linguistics and grammaticalization theory. In terms of the former, a better understanding of a seemingly puzzling distribution of a definite article, a rare word class in this language family, has been documented. It would not be surprising that the further grammaticalization of $k i$ had some connection (yet to be ascertained) with the fact that its existence constitutes an innovation from the point of view of Chibchan comparative grammar (that is, the peculiarity of having a definite article could in itself explain its further

${ }^{14} E^{\prime} t s e$ is the cardinal number 'one' in Boruca. This fact does not affect the analysis presented here because, the use of the number 'one' as indefinite is cross-linguistically well-attested (cf. Lehmann 1995: 50 f, among others). 
development, as evidenced by the fact that no other Chibchan language has grammaticalized SPECIFICITY). As for the latter, further evidence has been provided for both the claim that synchronic variation/distribution can be better accounted for dynamically, that is, as part of an ongoing process, and for the grammaticalization channel DEFINITE ARTICLE $>$ SPECIFIER ( $>$ SUBJECT). A better understanding of the grammar of reference in language in general, and in Boruca in particular has thus been attained.

\section{References}

COMRIE, BERNARD. (1989). Language universals and linguistic typology. Oxford: Blackwell.

CONSTENLA, Adolfo AND MAROTO. E SPÍRITU SANTO. 1986. Leyendas y tradiciones borucas. San José: Editorial Universidad de Costa Rica.

GIVÓN, TALMY. 1976. "Topic, pronoun and grammatical agreement”. In Li, C. (ed.) Subject and Topic. New York: Academic Press: 149-188.

1984. Syntax: A Functional-Typological Introduction. Vol. 1. Amsterdam: Benjamins.

GREENBERG, JOSEPH. 1978. How does a language acquire gender markers? Universals of Human Language, Vol. 3, ed. by Greenberg, J., Ferguson, C. and Moravcsik, E. Stanford: Stanford University Press: 47-82.

HEINE, BERND. 1992. Grammaticalization chains. Studies in Language 16 (2), 335-368. . 1994. "Grammaticalization as an Explanatory Parameter". In Pagliuca, W. (ed.) Perspectives on Grammaticalization. Amsterdam/Philadelphia. John Benjamins: 255-281.

HeInE, BERnd ET AL. 1991a. Grammaticalization: A Conceptual Framework. Chicago University Press.

. 1991b. "From cognition to Grammar -Evidence from African Languages". In Traugott, E. and B. Heine (eds.) 1991. Approaches to Grammaticalization. 2 Vols. Amsterdam/Philadelphia. John Benjamins. : 149-187.

Hopper, Paul and Elizabeth TraugotT. 1993. Grammaticalization. Cambridge University Press.

LEHMANN, Christian. 1982. "Universal and typological aspects of agreement". In Apprehension: das sprachliche Erfassen von Gegenständen. Seiler, H. and F.J. Stachowiak (eds.) Tübingen. Narr, Vol 2: 201-267.

1985. "Grammaticalization: Synchronic Variation and Diachronic Change", in: Lingua e Stile/a.20, 3: 303-318.

1995. Thoughts on Grammaticalization. Munich: LINCOM-EUROPA.

LYONS, JOHN. 1977. Semantics. Vol 1. Cambridge University Press.

Mufwene, SAliKOKO. 1980. "Number, Countability and Markedness in Lingala li-/ma Noun Class". Linguistics 18, 1019-1052.

. 1981. "Non-Individuation and the Count/Mass Distinction". Papers from the 17. Regional Meeting of the Chicago Linguistic Society: 221-238.

QueSADA, J. DiEGO. (in progress). "The grammar of participant-highlighting and the grammmaticalization of subject morphology in Boruca". 1999. "Chibchan: with special attention to the domain of participant highlighting". Linguistic Typology 3: 209-258. 
. 1995. "Case, Agreement and Topicality in Spanish". Orbis 35: 60-79.

QuesadA, J. Diego And Miguel A. Quesada-Pacheco. 1995. "Boruca ki y la hipótesis de las funciones contiguas". Estudios de lingüistica chibcha 14: 89-99.

StraWson, P. F. 1950/1993. "On Referring”. In Moore, A.W. (ed.) 1993. Meaning and Reference. Oxford University Press: 56-79. 